\title{
MORFOLOGIA FLORAL E BIOLOGIA REPRODUTIVA DE GENÓTIPOS DE ACEROLEIRA
}

\author{
José Everaldo Gomes ${ }^{1}$; Maria do Carmo M.D. Pavani; Dilermando Perecin¹; Antônio Baldo \\ Geraldo Martins ${ }^{3}$ \\ ${ }^{1}$ Depto. Ciências Exatas FCAVJ/UNESP, Via de Acesso Prof. Paulo Donato Castellane s/n - CEP: 14884-900 - \\ Jaboticabal, SP. \\ ${ }^{2}$ Depto. de Biologia Aplicada à Agropecuária - FCAVJ/UNESP. \\ ${ }^{3}$ Depto. de Produção Vegetal da FCAVJ/UNESP \\ *Autor correspondente <mcarmo@fcav.unesp.br>
}

\begin{abstract}
RESUMO: Estudos sobre morfologia floral e biologia reprodutiva de uma cultura contribuem para o desenvolvimento de técnicas de castração e polinização. Com este propósito, estudaram-se a estrutura e a biologia floral em cinco genótipos de aceroleira (Malpighia emarginata), em Jaboticabal, SP; no período de dezembro/97 a janeiro/99. Foi avaliada a morfologia floral, por caracterização e quantificação, e a biologia reprodutiva, desde o aparecimento dos primórdios do botão floral até a abertura. As flores da aceroleira são monóclinas, com cálice composto por seis a sete sépalas, corola de cinco pétalas, nove a dez glândulas presentes na base, androceu com dez estames e gineceu com três a quatro pistilos e distribuem-se em cimeiras axilares com 3 a 13 flores nos ramos do ano anterior e do mesmo ano. Verificaram-se de 6 a 7 floradas por ano, principalmente de janeiro a maio e de agosto a dezembro, registrando-se que desde 0 aparecimento do botão floral à antese decorrem 6,9 a 7 dias, com abertura floral entre 5 h00 e 8 h00 e das $14 \mathrm{~h} 00$ às $16 \mathrm{~h} 00$, com floração de 22,1 a 29,4 dias, decorrendo do florescimento à maturação do fruto 22 dias e duração da colheita de 19,7 a 28,8 dias.
\end{abstract}

Palavras chave: Malpighia emarginata, floração, morfologia

\section{FLOWER MORPHOLOGY AND REPRODUCTIVE BIOLOGY OF WEST INDIAN CHERRY GENOTYPES}

\begin{abstract}
Flower morphology and reproductive biology knowledge of fruit crops may contribute to the development of castration and pollination tecniques. With this objective, flower structure and the biology of West Indian cherry genotypes were studied at Jaboticabal, SP, Brazil. Flower morphology was evaluated by characterization, quantification and reproductive biology, from flower bud beginning until opening. West Indian Cherry flower is hermaphrodite with a calix of six or seven sepals, corolla of five petals, nine or ten glands in the lower region, ten stamen androecium and gyneceum with three or four pistils. The flowers are distributed in bunches of 3 to 13 units each, on the same year or on the latest year branches. Plants flower 6 to 7 times per year, mainly from January to May and August to December periods, with about 7 days elapsed from flower bud appearance to anthesis, wich occurs from $5 \mathrm{~h} 00$ to $8 \mathrm{~h} 00 \mathrm{AM}$ and from $2 \mathrm{~h} 00$ to $4 \mathrm{~h} 00 \mathrm{PM}$. The flowering period endures from 22.1 to 29.4 days. The fruit ripeness occurs 22 days after flowering and the crop lasts 19.7 to 28.8 days.
\end{abstract}

Key words: Malpighia emarginata, flowering, morphology

\section{INTRODUÇÃO}

O conhecimento da estrutura floral e da biologia reprodutiva numa cultura é básico para que o melhorista desenvolva técnicas de castração e polinização adequadas. Segundo Damião Filho (1993), o rápido progresso alcançado no melhoramento das plantas cultivadas se deve aos estudos dos processos reprodutivos que ocorrem nas flores.

Asenjo (1980), frente a estudos de acerola nos herbários de Linneau, reporta que os nomes $M$. glabra e $M$. punicifolia são sinônimos, porém, aplicados a uma espécie diferente da acerola; devendo-se chamar corretamente a acerola de Malpighia emarginata DC. Nogueira (1997), estudando as expressões fisiológicas da aceroleira enviou diversas amostras para Dr. Willian R. Anderson, especialista na família Malpighiaceae, que constatou tratar-se de uma única espécie, $M$. emarginata DC., utilizada corretamente para designar acerola e ressaltou que Malpighia glabra, não é uma espécie cultivada por apresentar frutos insípidos. Tal informação corrobora a nomenclatura utilizada por Alves (1993), que trabalhou com frutos de planta cultivada em Jaboticabal, SP.

A aceroleira (Malpighia emarginata DC.) é um arbusto possuidor de haste única, ramificações densas, de crescimento longitudinal e/ou lateral (Araújo \& Minami, 1994). As flores são dispostas em cimeiras axilares (Miyashita et al., 1964) e pedunculadas com $2-8$ flores (Araújo \& Minami, 1994) de coloração variável desde o 
rosa esbranquiçado ao vermelho, conforme o genótipo (Simão, 1971); o cálice possui de 6 a 10 sépalas (Simão, 1971; Couceiro, 1985; Marino Netto, 1986), com 6 a 10 glândulas circundando suas faces externas (Araújo \& Minami, 1994), característica determinante das Malpighiaceae; a corola possui cinco pétalas franjadas ou irregularmente dentadas com garras finas, sendo quatro de mesmo tamanho, e a quinta maior em relação às demais (Simão, 1971; Araújo \& Minami, 1994). Apresenta ainda dez estames perfeitos com filamentos unidos na parte inferior (Simão, 1971); gineceu tricarpelar, ovário globular, súpero, fusionado com três lóculos e três pistilos que se apresentam eretos, de mesmo tamanho, em forma de anzol e com a superfície estigmática no ângulo interno (Araújo \& Minami, 1994).

As flores desenvolvem-se nos ramos de vegetação do ano anterior e nos ramos novos após um surto de crescimento vegetativo (Gonzaga Neto \& Soares, 1994), decorrendo sete dias desde o aparecimento do botão floral à antese da flor, que está diretamente relacionada à temperatura, verificando-se freqüentemente nas regiões tropicais, de 6 a 8 períodos de floradas- frutificações/ano (Araújo \& Minami, 1994).

Simão (1971) reporta estudos sobre a receptividade do estigma e sobre a deiscência da antera, esclarecendo que não ocorre dicogamia, o que possibilita a oportunidade de autopolinização bem como a polinização cruzada. Em adição, Araújo \& Minami (1994) relatam que a deiscência da antera está estreitamente relacionada à antese nos clones de acerola número 21 e Florida Sweet.

A formação do fruto é rápida, abrangendo 22 dias desde o florescimento até a maturação (Simão, 1971; Couceiro,1975; Marino Netto, 1976; Batista et al., 1991).

Foi objetivo do trabalho a realização de estudos comparativos da morfologia floral e biologia reprodutiva em cinco genótipos de aceroleira a fim de se obter informações que contribuam para o desenvolvimento de técnicas de castração e polinização na cultura.

\section{MATERIAL E MÉTODOS}

O experimento para estudo da morfologia floral e biologia reprodutiva da acerola foi conduzido no pomar da Faculdade de Ciências Agrárias e Veterinárias de Jaboticabal (FCAVJ), situada a $21^{\circ} 5$ ' 22 " de latitude sul, $48^{\circ} 18^{\prime} 58^{\prime \prime}$ de longitude oeste e altitude de $575 \mathrm{~m}$. Selecionaram-se para as avaliações cinco genótipos de M. emarginata, denominados CL2, CL5, CL11, R1 e R2, segundo análises prévias dos caracteres de interesse agronômico, tais como produção, arquitetura da planta (diâmetro de copa e altura do arbusto), tamanho dos frutos (altura e diâmetro).

Os estudos da morfologia floral (Figura 1) foram desenvolvidos no período de dezembro de 1997 a janeiro de 1999 e as análises basearam-se nos conceitos de Damião Filho (1993), avaliando-se, a cada florada espontânea, a caracterização morfológica e a quantificação das estruturas componentes dos verticilos florais (cálice, corola, androceu e gineceu) e glândulas.

Avaliou-se, no mesmo período, a biologia reprodutiva da flor segundo observações dos autores deste trabalho, através de dias decorridos desde 0 aparecimento do botão floral à abertura, da caracterização do botão intumescido, do número de flores/inflorescência, sincronia floral, tipo de floração, intervalo de tempo entre abertura (antese) e a despétala das flores, da receptividade do estigma após a antese, épocas de floracão, número de dias em floração, dias decorridos do florescimento à colheita do fruto, número de floradas/ano e dias em colheita.

Para mensuração de dias decorridos desde 0 aparecimento dos primórdios do botão à antese da flor (DDABA) foram selecionados cinco botões/genótipo em um mesmo dia e observados até a abertura.

O diagnóstico "botão intumescido" foi fornecido por observação visual de turgescência máxima atingida pelo botão até que iniciasse sua abertura. $O$ número de flores/inflorescência (NF/IF) foi contabilizado pela contagem individual de flores em dez inflorescências. A sincronia floral e o tipo de floração foram avaliados por observações períodicas. O intervalo de tempo entre a antese e a despétala das flores foi analisado em dez botões previamente marcados desde seu processo de abertura até que a última pétala se desprendesse ou murchasse.

Para o diagnóstico da receptividade do estigma e tempo para tal ocorrência foram avaliadas dez flores desde a antese, quando o ápice dos pistilos se deslocavam do ponto central em direção às laterais e apresentavam a superfície estigmática viscosa e com brilho, até o momento em que se tornava opaca e/ou ocorresse 0 arqueamento do ápice dos pistilos para 0 centro.

As épocas de floração foram analisadas para cada genótipo, desde o dia da abertura da primeira até a antese da última flor na planta, contabilizando-se em dias o tempo de floração (NDFL).

Para a mensuração do número de dias decorridos do florescimento à colheita (DDF-C), 20 botões em antese de cada genótipo foram avaliados periodicamente até a maturação do fruto.

$\mathrm{O}$ número de floradas/ano (NF/A) é referente às épocas em que os genótipos floresceram e o número de dias em colheita (DC) é a contagem do tempo, em dias, desde o aparecimento dos primeiros frutos maduros até a queda do último fruto.

Para embasamento dos resultados e discussão, elaboraram-se três tabelas, cujos dados relativos aos genótipos estudados foram comparados entre si e com a literatura existente. 


\section{RESULTADOS E DISCUSSÃO}

As flores da aceroleira são pedunculadas e distribuídas em cimeiras axilares, como descrito por Miyashita et al. (1964). Apresentam coloração variável desde o rosa esbranquiçado ou lilás claro (CL2) até o vermelho (R1), com distribuição cíclica das peças no receptáculo e são diclamídeas quanto à presença dos verticilos protetores. Os estames, cujo filete possui inserção basifixa, são de mesmo tamanho e as anteras apresentam fendas de deiscência longitudinal ou rimosas, com duas tecas. O ovário súpero e a flor monóclina sugerem certa taxa de autofecundação, desde que não ocorra auto-incompatibilidade. Verificou-se também que não há dicogamia na acerola (Figura 1).

Segundo Allard (1971), em experimentos para determinação da taxa de autogamia e alogamia em distintas culturas, numa primeira etapa, o exame da estrutura floral revela a alogamia, quando a dioicia, dicogamia e/ou monoeicia ocorrem na flor. Em relação à acerola, colocase ainda que, durante o processo de antese, a última pétala (quinta) aprisiona os pistilos e três dos estames até que se processe sua abertura completa (Figura 2), reforçando a tese de que existe certa taxa de autofecundação.

O número de sépalas e de glândulas que circundam a base da flor, varia de 6 a 7 e de 9,3 a 10 , respectivamente, confirmando os dados relatados por Simão (1971), Couceiro (1985) e Marino Netto (1986). Observou-se uniformidade do número de sépalas do genótipo CL11 e do número de glândulas do genótipo R2 (TABELA 1). Quanto ao número de pétalas e de estames houve uniformidade numérica e plena para todos os genótipos (TABELA 1), ocorrência também esperada quanto ao número de estames, que varia entre flores de espécies diferentes, mas é constante dentro da espécie (Damião Filho, 1993). Com relação ao número de pistilos (TABELA 1), observou-se no genótipo CL5 a presença de três a quatro, diferentemente do que foi observado nos demais genótipos estudados, estes consonantes com os dados de Araújo \& Minami (1994), que registraram um número constante de três.

As flores desenvolvem-se nos ramos do ano anterior e do mesmo ano, nas ramificações periféricas e internas da planta, decorrendo-se 6,9 a 7 dias desde o aparecimento do botão floral até a antese, embora haja tendência de redução neste tempo para os genótipos CL5, CL11 e R1 durante os meses quentes e chuvosos, janeiro a março (TABELA 2).

Quanto ao caráter número de flores/ inflorescência (TABELA 2), nota-se grande dispersão númerica, tanto dentro como entre os genótipos, o mesmo ocorrendo com relação ao número de dias em

TABELA 1 - Média e coeficiente de variação nas variações da morfologia floral de cinco genótipos de aceroleira, avaliados de dezembro/97 a janeiro/99, em Jaboticabal, SP.

\begin{tabular}{|c|c|c|c|c|c|c|c|c|c|c|}
\hline \multirow{4}{*}{ Genótipo } & \multicolumn{10}{|c|}{ Variável morfológica da flor } \\
\hline & \multicolumn{4}{|c|}{ Cálice } & \multirow{2}{*}{\multicolumn{2}{|c|}{$\begin{array}{l}\text { Corola } \\
\text { pétala }\end{array}$}} & \multirow{2}{*}{\multicolumn{2}{|c|}{$\begin{array}{c}\text { Androceu } \\
\text { estame } \\
\end{array}$}} & \multirow{2}{*}{\multicolumn{2}{|c|}{ Gineceu }} \\
\hline & \multicolumn{2}{|c|}{ sépala } & \multicolumn{2}{|c|}{ glândula } & & & & & & \\
\hline & $\bar{X}$ & CV & $\overline{\bar{X}}$ & $\mathrm{CV}$ & $\overline{\bar{X}}$ & $\mathrm{CV}$ & $\overline{\bar{X}}$ & $\mathrm{CV}$ & $\bar{X}$ & $\mathrm{CV}$ \\
\hline CL2 & 6,5 & 8,43 & 9,3 & 5,53 & 5 & 0,0 & 10 & 0,0 & 3 & 0,0 \\
\hline CL5 & 6,2 & 6,20 & 9,6 & 5,60 & 5 & 0,0 & 10 & 0,0 & 3,3 & 14,9 \\
\hline CL11 & 6,0 & 0,00 & 9,4 & 5,70 & 5 & 0,0 & 10 & 0,0 & 3 & 0,0 \\
\hline R1 & 6,5 & 8,20 & 9,4 & 7,90 & 5 & 0,0 & 10 & 0,0 & 3 & 0,0 \\
\hline R2 & 7,0 & 0,00 & 10,0 & 0,00 & 5 & 0,0 & 10 & 0,0 & 3 & 0,0 \\
\hline
\end{tabular}

$\bar{X}$ : media CV: coeficiente de variação

TABELA 2 - Média e coeficiente de variação nas variáveis da biologia reprodutiva em cinco genótipos de aceroleira, avaliados de dezembro/97 a janeiro/99, em Jaboticabal, SP.

\begin{tabular}{|c|c|c|c|c|c|c|c|c|c|c|c|}
\hline \multirow{3}{*}{ Ge nótipo } & \multicolumn{11}{|c|}{ Variável de biologia reprodutiva } \\
\hline & \multicolumn{2}{|c|}{ DDABA } & \multicolumn{2}{|c|}{$\mathrm{NF} / \mathrm{IF}$} & \multicolumn{2}{|c|}{ NDFL } & \multicolumn{2}{|c|}{ DDF-C } & \multirow{2}{*}{$N F / A$} & \multicolumn{2}{|c|}{$\mathrm{DC}$} \\
\hline & $\bar{X}$ & $\mathrm{CV}$ & $\bar{X}$ & CV & $\bar{X}$ & $\mathrm{CV}$ & $\bar{X}$ & $\mathrm{CV}$ & & $\bar{X}$ & CV \\
\hline CL2 & 7 & 0,0 & 7,0 & 47,2 & 27,2 & 40,5 & 22,7 & 5,4 & 6 & 19,7 & 48,0 \\
\hline CL5 & 6,9 & 5,5 & 8,6 & 36,8 & 29,4 & 30,1 & 22,5 & 5,7 & 7 & 23,0 & 23,0 \\
\hline CL11 & 6,9 & 5,5 & 3,9 & 23,3 & 22,1 & 46,5 & 20,8 & 19,1 & 6 & 28,8 & 51,5 \\
\hline R1 & 6,9 & 5,2 & 8,5 & 29,5 & 22,6 & 16,2 & 22,8 & 5,7 & 6 & 24,2 & 17,9 \\
\hline R2 & 7 & 0,0 & 8,4 & 31,2 & 22,8 & 15,3 & 23,0 & 5,3 & 6 & 24,0 & 22,7 \\
\hline
\end{tabular}

DDABA: dias decorridos desde o aparecimento dos primórdios do botão floral à antese; NF/IF: número de flores por inflorescência; NDFL: número de dias em floração; DDF-C: dias decorridos do florescimento à colheita do fruto; NF/A: número de floradas / ano; DC: dias em colheita; $\bar{X}$ : média; CV: coeficiente de variação 
floração e dias de colheita. Isto sugere que ocorre resposta particularizada de cada genótipo às condições meteorológicas.

Para o caráter número de dias decorridos da floração à colheita, nos genótipos CL2, CL5, R1 e R2 a dispersão é baixa, e em CL11, a dispersão é média, reforçando a teoria de Batista et al. (1991) que afirmaram ser rápida a formação dos frutos, abrangendo 22 dias do florescimento à maturação, o que possibilita 6 a 7 floradas/ano ou mais, conforme as condições meteorológicas locais (TABELA 2).

O botão floral é considerado intumescido quando as cicatrizes das pétalas estão visíveis e marcadas com um ponto de convergência central (Figura 3). A sincronia floral processa-se por cimeira de fora para dentro (centrípeta), podendo ser observada na mesma inflorescência ou em inflorescências da mesma planta a antese simultânea e/ou ao longo do dia, constatando-se maior incidência nas primeiras horas da manhã e no período das $14 \mathrm{~h} 00$ às $16 \mathrm{~h} 00$, com alta luminosidade (TABELA 3).

Nas condições de Jaboticabal, SP, as floradas são freqüentes nos meses de janeiro até o início de maio e da segunda quinzena de agosto a dezembro, períodos relativamente quentes e chuvosos. Nos meses de maio a julho, quando ocorre o período frio, as plantas encontram-se em repouso, tendendo a perder a cobertura foliar com intensidade dependente do rigor do frio e da adaptabilidade do genótipo (TABELA 3).

TABELA 3 - Horário de abertura floral, de despétala e registro cronológico das observações em cinco genótipos de aceroleiras, avaliados de dezembro/97 a janeiro/99, em Jaboticabal, SP.

Variável da biologia reprodutiva

Horário de Abertura e despétala

\begin{tabular}{|c|c|c|c|c|}
\hline Ge nótipo & Abertura & Despétala & Período e & m floração \\
\hline \multirow{6}{*}{ CL2 } & $06 \mathrm{~h} 00$ & $18 \mathrm{~h} 00$ & 25.11 .97 & a 05.01 .98 \\
\hline & 09h00 & $21 \mathrm{~h} 00$ & 03.02 .98 & a 25.02 .98 \\
\hline & 08h00 & $20 \mathrm{~h} 00$ & 31.03 .98 & a 10.05 .98 \\
\hline & 07h00 & $19 h 00$ & 04.09 .98 & a 18.09 .98 \\
\hline & $14 \mathrm{~h} 00$ & $02 \mathrm{~h} 00$ & 16.10 .98 & a 10.11 .98 \\
\hline & $16 \mathrm{~h} 50$ & 04h00 & 06.12 .98 & a 29.12 .98 \\
\hline \multirow{7}{*}{ CL5 } & 08h00 & 20h10 & 10.12 .98 & $a-$ \\
\hline & 07h00 & $19 \mathrm{~h} 00$ & 28.03 .98 & a 24.04 .98 \\
\hline & $12 \mathrm{~h} 00$ & $23 \mathrm{~h} 40$ & 31.08 .98 & a 25.09 .98 \\
\hline & 08h00 & $20 \mathrm{hO0}$ & 16.10 .98 & a 20.11 .98 \\
\hline & 09h00 & $20 h 30$ & 09.12 .98 & a 15.01 .99 \\
\hline & $10 \mathrm{~h} 00$ & $22 \mathrm{~h} 10$ & & - \\
\hline & $16 \mathrm{~h} 00$ & 04h00 & & - \\
\hline \multirow{6}{*}{ CL11 } & 05h00 & $11 \mathrm{~h} 00$ & 27.11 .97 & a 18.12 .97 \\
\hline & 07h00 & $20 h 40$ & 19.03 .98 & a 08.04 .98 \\
\hline & $14 \mathrm{~h} 00$ & 02h00 & & - \\
\hline & 08h00 & $20 \mathrm{~h} 00$ & 04.09 .98 & a 28.09 .98 \\
\hline & $16 \mathrm{~h} 00$ & 04h00 & 16.10 .98 & a 23.11 .98 \\
\hline & 08h00 & $20 \mathrm{~h} 00$ & 19.12 .98 & a 06.01 .98 \\
\hline \multirow{7}{*}{$\mathrm{R} 1$} & $15 \mathrm{~h} 00$ & $02 \mathrm{~h} 40$ & & - \\
\hline & $16 \mathrm{~h} 00$ & 04h00 & & - \\
\hline & 08h00 & $19 \mathrm{~h} 50$ & 10.02 .98 & a 03.03 .98 \\
\hline & 09h00 & $21 \mathrm{~h} 00$ & 25.03 .98 & a 14.04 .98 \\
\hline & $11 \mathrm{~h} 00$ & 23h05 & 21.08 .98 & a 10.09 .98 \\
\hline & $09 \mathrm{~h} 00$ & $20 \mathrm{~h} 05$ & 16.10 .98 & a 13.11 .98 \\
\hline & $14 \mathrm{~h} 00$ & $02 \mathrm{~h} 00$ & 07.12 .98 & a 29.12 .98 \\
\hline \multirow{6}{*}{$\mathrm{R} 2$} & $08 \mathrm{~h} 00$ & $20 \mathrm{~h} 05$ & 10.02 .98 & a 05.03 .98 \\
\hline & $14 \mathrm{~h} 00$ & $02 \mathrm{~h} 00$ & 25.03 .98 & a 14.04 .98 \\
\hline & $16 \mathrm{~h} 00$ & $03 \mathrm{~h} 50$ & 21.08 .98 & a 15.09 .98 \\
\hline & $18 \mathrm{~h} 00$ & 06h00 & 18.10 .98 & a 18.11 .98 \\
\hline & $14 \mathrm{~h} 00$ & $02 \mathrm{~h} 00$ & 08.12 .98 & a 30.12 .98 \\
\hline & $13 \mathrm{~h} 40$ & $02 \mathrm{~h} 00$ & & - \\
\hline
\end{tabular}

-: sem observações 


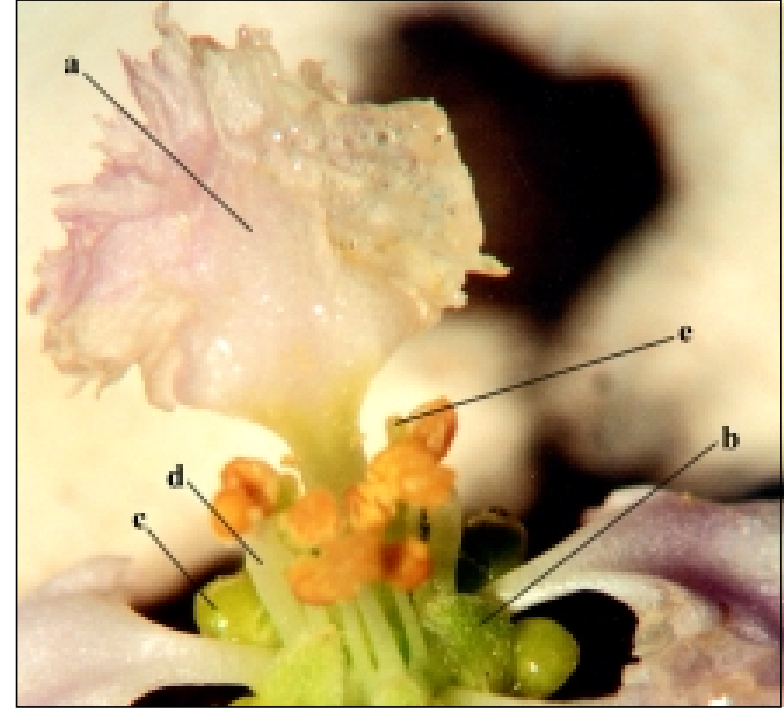

Figura 1 - Aspectos morfológicos da flor da aceroleira. a. pétala principal; b. sépala; c.glândula; d. estame ; e. pistilo.

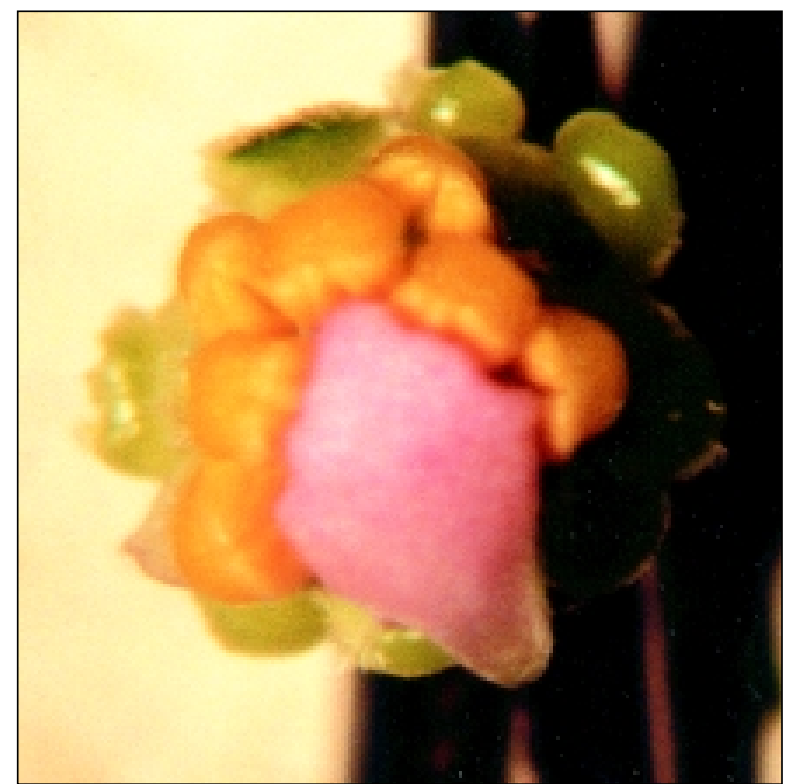

Figura 2 - Posição dos estames e dos pistilos de aceroleira em relação à Quinta pétala.

\section{CONCLUSÕES}

Ocorrem de 6 a 7 floradas por ano, principalmente de janeiro a maio e de agosto a dezembro. Desde o aparecimento do botão floral à antese decorrem 6,9 a 7 dias, com abertura floral entre $5 \mathrm{~h} 00$ e $8 \mathrm{~h} 00$ e das $14 \mathrm{~h} 00$ às $16 \mathrm{~h} 00$ e com período de floração de 22,1 a 29,4 dias, decorrendo do florescimento à maturação do fruto 22 dias, com duração da colheita de 19,7 a 28,8 dias.

\section{AGRADECIMENTOS}

À FAPESP, Fundação de Amparo à Pesquisa do Estado de São Paulo pela concessão de bolsa e apoio ao projeto.

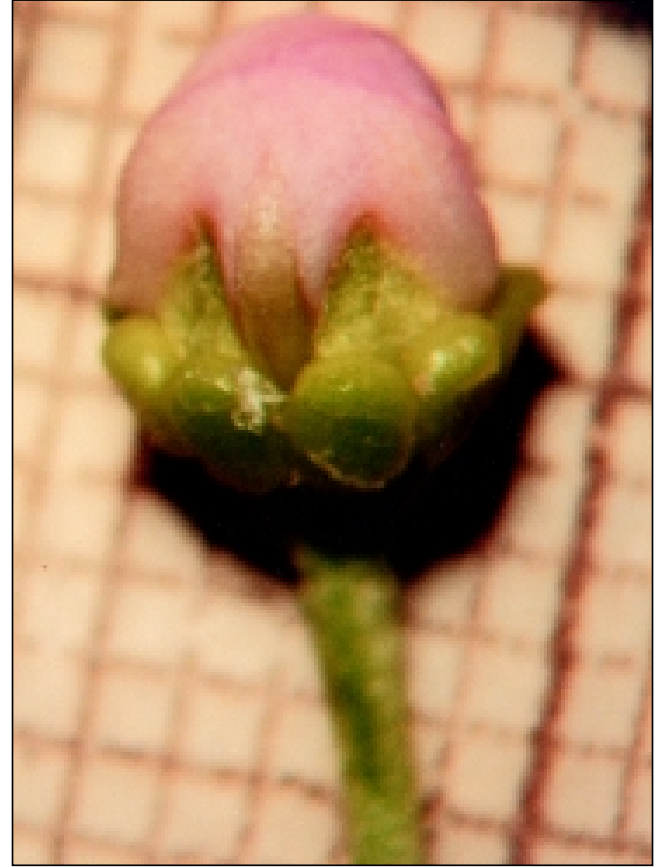

Figura 3 - Botão floral intumescido apto à castração.

\section{REFERÊNCIAS BIBLIOGRÁFICAS}

ALLARD, R.W. Princípios do melhoramento genético das plantas. São Paulo: Edgard Blucher,1971.381p.

ALVES, R.E. Acerola (Malpighia emarginata DC.): fisiologia da maturação e armazenamento refrigerado sob atmosfera ambiente modificada. Minas Gerais, 1993. 99p. Tese (Mestrado) - Escola Superior de Agricultura de Lavras.

ARAÚJO, P.S.R. de.; MINAMI, K. Acerola. Campinas: Fundação Cargill, 1994. 8 p.

ASENJO, C.F. Acerola. In: NAGY, S.; SHAW, P.E. Tropical and subtropical fruits: composition, properties and uses. Westport: AVI, p.341-374, 1980.

BATISTA, F.A.S.; MUGUET, B.R.R.; BELTRÃO, A.E.S. Comportamento e seleção da aceroleira na Paraíba. In: CONGRESSO BRASILEIRO DE FRUTICULTURA, 9., Fortaleza, 1989. Anais. Fortaleza: SBF; BNB, 1991. p.26-32.

COUCEIRO, E.M. Curso de extensão sobre a cultura da acerola. Recife: UFRPE, 1985. 45p.

DAMIÃO FILHO, C.F. Morfologia vegetal. Jaboticabal: FUNEP; UNESP, 1993. 243p.

GONZAGA NETO, L.; SOARES, J.M. Acerola para exportação: aspectos técnicos da produção. Brasília: EMBRAPA, SPI; CPATSA; FRUPEX; DENACOOP, 1994. 43p.

MARINO NETTO, L. Acerola: a cereja tropical. São Paulo: Nobel, 1986. 94p.

MIYASHITA, R.K.; NAKASONE, H.Y.; LAMOUREUX, C.H. Reproductive morphology of acerola (Malpighia glabra L.). Honpluiu: University of Hawaii, Hawaii Agricultural Experiment Station, 1964. 28p. (Technical Bulletim, 63)

NOGUEIRA, R.J.M.C. Expressões Fisiológicas da Aceroleira (Malpighia emarginata DC.) em condições adversas. São Carlos, 1997. 207p. Tese (Doutorado) - Universidade de São Carlos.

SIMÃO, S. Cereja das Antilhas. In: SIMÃO, S. Manual de fruticultura. São Paulo: Agronômica Ceres, 1971, p.477-485.

Recebido em 05.06.00 